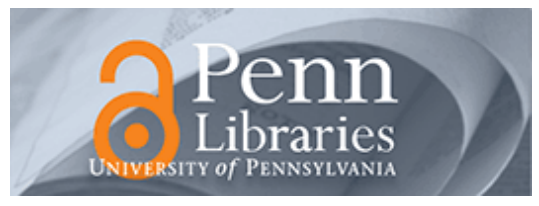

Studies in Visual Communication

Volume 11

Issue 3 Summer 1985

Article 4

1985

\title{
Visual Contexts: A Photographic Research Method in Anthropology
}

Victor J. Caldarola

\section{Recommended Citation}

Caldarola, V. J. (1985). Visual Contexts: A Photographic Research Method in Anthropology. 11 (3), 33-53.

Retrieved from https://repository.upenn.edu/svc/vol11/iss3/4

This paper is posted at ScholarlyCommons. https://repository.upenn.edu/svc/vol11/iss3/4

For more information, please contact repository@pobox.upenn.edu. 


\section{Visual Contexts: A Photographic Research Method in Anthropology}




\title{
Visual Contexts: A Photographic Research Method in Anthropology
}

\author{
Victor J. Caldarola
}

We tried to shoot what happened normally and spontaneously, rather than to decide upon the norms and then get Balinese to go through these behaviors in suitable lighting. We treated the cameras in the field as recording instruments, not as devices for illustrating our theses.

- Gregory Bateson (Bateson and Mead 1942:49)

Recent studies in anthropology and photography theory have promoted in various ways a reexamination of the process of observation and analysis. By incorporating the notion of appropriate process into the model of photographic representation, it is possible to construct a very useful method of photographic investigation.

The relevant theory includes a diverse set of viewpoints. In anthropology, Salamone (1979:51) suggested that the "contexts of fieldwork" be examined in order to control for bias; Jarvie (1975:264) urged a more ambitious "anthropology of anthropology"; while Myerhoff and Ruby $(1982: 2,5)$ offered a "reflexive" approach that would include the "producer," "process," and "product" of anthropological research. Similarly in photography, Sekula (1975:38) showed that photographic meaning is intrinsically dependent on the "discourse situation" of image production and presentation, while Snyder and Allen (1976:13) demonstrated that the representational value of a photograph depends on the photographer, his intentions, and his working methods. Finally, pertaining more specifically to the cross-fertilization of anthropology and photography, Ruby (1975:108-109; 1976:6-7) and Worth $(1980: 15,20 ; 1982: 37)$ suggested that photographic and filmic meaning exist in the social and methodological contexts of image articulation and interpretation.

It is clear that photographic methods based on culturally conventional patterns of medium utilization are inappropriate for anthropological inquiry, and that the basic photographic response must be revised in order to make the image-producing process compatible with anthropological paradigms. ${ }^{1}$ The photographic research method proposed here is such a revised response and may be described as a program for investigating the visual components of anthropological problems. An adjunctive methodology designed to be implemented in collaboration with an anthropologist working in the verbal tradition, the program focuses

Victor J. Caldarola is a Master of Arts candidate at The Annenberg School of Communications, University of Pennsylvania. He has worked professionally as an archaeological photographer and is currently interested in the nature of communication and representation in ethnographic research. on the essential difficulties of research communication via the photographic media: (1) the epistemology of photographic representation, (2) the nature of the observation process, and (3) the conceptualization of photographic data with regard to their function and validity.

The methodology will be presented in some detail first, followed by a report on its implementation as part of an anthropological investigation initiated by my wife, Patricia J. Vondal. Our particular research problem concerned an agricultural industry in the Hulu Sungai region of South Kalimantan, Indonesia, an industry distinguished by its extraordinary impact on regional economic development. The core research program was designed to examine the social, economic, and ecological factors contributing to the industry's marked success (Vondal 1984:1). ${ }^{2}$

\section{The Photographic Research Method}

The photographic research method is derived largely from a particular epistemological conception of photographic representation, which may be summarized by the following premises: (1) that photographic images are event-specific representations, (2) that their relevance or meaning is dependent upon the context of the image-producing event, and (3) that the imaging event is a socially interactive and communicative process that involves the mutual understanding and participation of both the observer and the observed. The nature of the observation process follows as a direct consequence of this epistemological framework.

The photographic research method focuses on specific events, much like the event-centered and circumstantial ethnography of Van Velsen (1967:139-140), Geertz (1973:23), and Goldschmidt (1972:59) and the classic photographic work of Bateson and Mead (1942:50). Each encounter is considered unique and nonrecurring, because the emphasis is on the actions of individuals in particular situations at particular times. The imaging process is observational, in that events are recorded as they occur and are not elicited or encouraged in any way. The photographer participates through photographic observation and produces a steady stream of images to record the event in time and space. It is an intensive and immediate form of observation that requires a willingness to photograph as a first response. Quick reflexes and a professional's familiarity with the equipment are distinct advantages.

Photographic coverage begins immediately upon entry into the field and continues for the duration of the fieldwork. Like cameraless observation, initial en counters are relatively naive but become more sophisticated as the research proceeds. Both the 


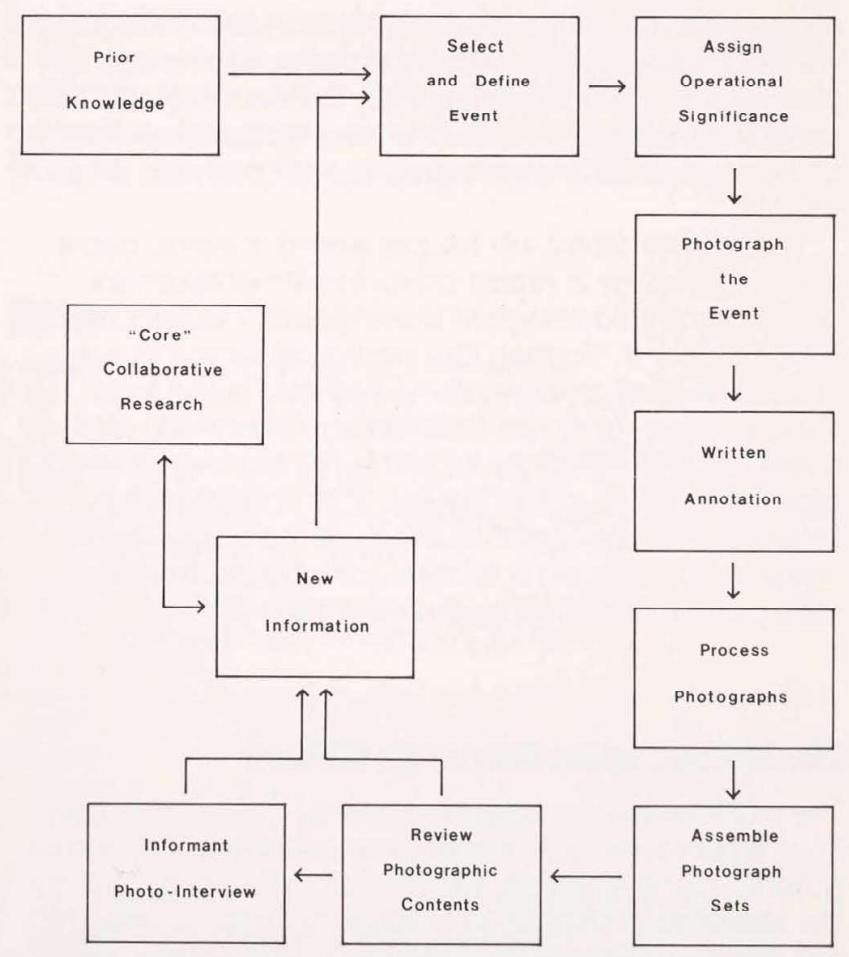

Figure 1 The Medium Application Cycle

quality of the observation and the sophistication of photographic data increase because of a repetitive cycle of photographic observation and review (see Figure 1). The medium application cycle is a conceptual model representing a single photographic event. It is based primarily on Spradley's (1980:29) "ethnographic research cycle" and provides a similar systematic technique for the accumulation and intensification of research data.

While the photographic research method is designed as a complete methodology, this paper will concentrate on the observation process. Observation produces the cumulative photographic record, which then functions as a data base for complex analysis and visual ethnographic description.

\section{Medium Application}

The medium application cycle begins in the planning stages of the research project. All available information is gathered, proposals prepared, and tentative plans noted. From this "prior knowledge," a preliminary photography plan is created that describes the proposed collaborative research design and includes an initial script of events and activities that lists worthwhile subjects for photographic coverage.
Selecting and Defining the Event. Once in the field, photographic observation begins by selecting and defining an event for coverage and assigning its significance. The selection is based on the researcher's prior knowledge of events of this type and on impressions at the earliest moments of interaction. The definition is purposefully cautious, tentative, and hypothetical. The event is defined via an "assigned significance," which is supplied by the researcher and noted briefly in a field notebook. This hypothetical definition is tested by photographing, review of the photographs, and informant interviews.

Selecting and defining the event before photographing places the photographic record into perspective and is a necessary if usually implicit procedure in photography (Szarkowski 1975:45; Snyder and Allen 1976:12). The photographer, like any critical observer, must describe an event in order to fix attention upon it (Cody 1967:166). It follows that what is described, or in this case photographed, is largely the result of the observer's initial definition.

Assigning Operational Significance. Once the event has been identified, the researcher must then decide which aspects of it to record. The operational significance, in the form of a "point of significance" and "boundaries," provides the researcher with guidelines based on the event's definition and perceived significance to the research. The guidelines provide a formal structure for photographic coverage - a plan of observation.

The point of significance is some central key or point upon which photographic coverage focuses. Boundaries may be physical, temporal, or particular to a person or object; they limit the scope of photographic coverage. The point/boundary framework allows comprehensive and responsive photographic recording while maintaining the event's assigned significance as a focal point. Later when the photographs are reviewed, the assigned significance functions as a frame of reference through which to critically assess the visual contents.

The significance annotation is central to the research program because it allows the photographer to approach an event without fully understanding it. The photography is "open-ended" within the limitations set by the point/boundary notation. The photographer does not have to understand the event as it occurs, only observe it through the formal structure. The understanding of it is documented by the definition. This framework permits a truly investigative photographic interaction. The accumulation of "undifferentiated data" (Sorenson 1967:445) through the establishment of specific reference points becomes possible and represents the heart of the photographic research method. Byers (1964) formally suggested the basis for this investigative system, although Bateson and Mead (1942:50) had used the technique with great success some twenty-five years earlier. 
Photographing the Event. Having noted the operational significance in writing, the photographer approaches the event and begins photographing. Photography centers on the interplay between elements of the scene and the central point of significance. This will vary depending on the static or dynamic quality of the designated event and can range from the physical context to the interaction among individuals. The basic photographing technique consists of a sequence format that combines detailed coverage with wide-field context in a relatively continuous series of photographs, each visually connected to the others.

Photography continues until the point of significance appears to change or the event exceeds its assigned boundaries. At this point coverage is reconsidered. If the event as it was originally identified by the assigned significance appears to conclude, photography follows suit. If the event appears to continue, a new point/boundary set is assigned and photography continues. A third possibility is that the first event may change into a different event that seems equally significant to the research, and this directly connected event is then photographed using a new point/boundary assignment.

Written Annotation. The assigned significance and the operational guidelines together represent the first step in the annotation process and are best recorded in a field notebook along with the numerical identification of the photograph series (roll, frame sequence, and date, or whatever film identification system is used). A single photographic event may have one or several point/boundary notations, but they are related by a single title that represents the event's overall assigned significance. The various point/ boundary photograph sets constituting a single event remain together throughout the research and analysis phases and in the permanent archive.

At some point after photographing, the interaction is documented by extensive written annotation. A separate annotative record is produced for each photographic event and includes the following

information:

1. the photographer's intention

2. the circumstances and arrangements of the encounter

3. a report on the photography

4. observations and conversations while on the scene

5. the individuals involved

The photographer's intention is already represented by the significance assignment, but it is useful to elaborate on it later. The circumstances and arrangements of the encounter are primarily an explanation of the photographer's presence: How did he come to be on the scene? In the report on the photography, the researcher explains why certain angles, certain equipment, and specific photographing strategies were chosen. Also included are the photographer's impression of the quality of the photographic record and the informants' responses to the photographer's presence and photographing activity. Observations and conversations while on the scene mean just that: what was observed and what discussions occurred. Finally, the individuals involved in the event or related in some way to the photographer's presence are noted by name or description.

The purpose of these "field notes" is to provide certain necessary baseline information so that the photographic records may be accurately assessed. These annotative data, along with the visual relationships recorded in the images, constitute the contextual elements pertaining to the specific photographic event and establish the basis of validity in the photographic data (Bateson and Mead 1942:49-50;

Newhall 1964:150; Sorenson 1968:181)

Assembling the Photograph Sets. After the photographs are processed, they are assembled into "analysis sets," each set reflecting a single photographic event. The photographs, in the form of individual proof prints, are assembled in the order in which they were made. Every frame is included without omission, editing, or rearrangement. The assembled analysis sets are dated and are assigned three-digit number codes according to the order in which they were produced

The analysis sets are used for content assessment, informant interviews, and all later analyses. Cross-referenced indexes are created during analysis so that specific subjects or photograph sets may be located, compared, and contrasted. Thus, the photographicevent/analysis-set construction provides access to the data, including the contents of the photographs and the researcher's image-producing activities

Review. The analysis sets are reviewed in light of their assigned significances and associated field notes. Elements of content especially apparent to the researcher during this review are noted along with identification and assembly. data for each analysis set. Each review, in addition, includes a section for further questions. These questions concern both specific details of the photographed event and topics for continuing research. Some may be used in photographic interviews with the informant, and some rep resent areas on which to focus further photographic coverage. In either case, these questions document aspects of the photographed event the researcher does not yet understand. 
Informant Interview. Where appropriate, photograph sets are brought to the informant who participated in the photographic event, and an interview is conducted based on the images. Usually, "feedback" interviews are conducted with known informants who have agreed to participate and to whom the photography program has been explained. The interview satisfies the participant's right of access to the photographs - they are informed beforehand that they will be able to view all photographs of themselves, their families, households, etc.- and encourages their active participation in the research program. The photographic interview enhances rapport and mutual trust by bringing the informant into the research process and demystifying the researcher's photographic activity.

The informant interview also expands the researcher's understanding of both visual and nonvisual areas Two basic types of questions may be asked. The first is directly related to the photographs' contents and is usually descriptive in nature: What do you call this object/activity/event? What are you doing here (referring to the photographs)? How exactly did you do it? What did you say? What is the purpose of this activity? The second uses the photographs as a point of departure by which to ask about things that are not literally represented in the images: Where did you learn to do this? When and how often does this occur? What is your profit margin? Is it always done the same way? How do you prepare for it? What happens afterward? Written records are kept of all interviews and are stored permanently with the analysis sets. Notes are included indicating the circumstances of the feedback interview: the location, the individuals present, and the informant's overall response to the photographs.

The first extensive use of informant feedback based on photographic records is usually attributed to Robert Flaherty when he was filming Nanook of the North in 1921-1922 (Rouch 1975:86; Heider 1976:23; Rotha and Wright 1980), although recent historical research places the inception of the technique with an early Boas expedition of 1886-1889 (Jacknis 1984). Flaherty screened the film's rushes to his Eskimo participants so they would "accept and understand what I was doing and work together with me as partners" (Flaherty diaries as quoted by Rotha and Wright 1980:43). This remains a very important goal of the feedback process and contributes significantly to the interactive approach of the photographic research method (Collier 1967:46-66; Rouch 1975:99).

New Information. Thus, hypotheses are tested first by photographically observing the event, then by reviewing the photographs in the context of the annotative record, and finally by informant photo-interviews where appropriate. The hypothesis-testing procedures produce not only the confirmed or revised hypotheses of the reviewed photograph sets, but also new questions upon which new hypotheses will be based, as well as an extensive body of related information. From this material, and information available from the ongoing collaborative research, the photographer once again selects events for photographic coverage, and the medium application cycle begins anew.

\section{Contexts of Photographic Interaction}

The medium application cycle generates data of multicontextual character. Among the associated records of each photographic event is included information about the contexts of research methodology, event conceptualization, event process and environment, researcher point of view, and informant response. The systematic nature of the observation process enhances the validity of data collection so that every photograph and annotative reference is a function of every other image and reference. The result is a contextual web that reflects the research theme and effectively increases the information content of any particular image (Mead 1970:247). Photographic data is defined therefore as the visual contents of the photographs viewed in the context of the photographic event that produced them.

On a somewhat different level, the process of event selection involves another form of context. Though general event types may be selected by using photography scripts, choosing a particular event for observation is somewhat more complicated. In short, each particular event is selected because it is connected to other events in some conceptually significant manner. The newly selected event is part of another event's social, physical, or functional context, and they are related by some known connection (Van Velsen 1967:147). The previous event or the point of connection should have been photographed already or at least observed and specifically noted. Events may be part of each other's connective context through a wide variety of possible links involving individuals, families, associates, or possessions; or by a particular location or time slot; or by some functional connection.

Connective context adds another dimension to the visual data and serves a validative as well as methodological function. The validative function is much like that generally applied to qualitative data in anthropology (Mead 1962:408-409), while methodologically, connective context constitutes a research method by which to investigate process and organization of broad phenomena through the specific connections between and among individual activities (Vayda 1983). 
Finally, normative pattern is recognized through a data interpretation process in which photograph sets are compared and contrasted, and conclusions are drawn. Remember that the medium application cycle is structured specifically to maximize the undifferentiated data content of the photographic and annotative records, which makes these materials suitable as continuing sources of discovery (Sorenson 1968:177). The visual data, then, are not finite and discrete, but depend on the interpretations and reinterpretations of the researcher. The interpretive process builds ethnographic understanding beyond the limits of any particular photographic event.

\section{Implementing the Methodology}

As a collaborative methodology, the photography program shared certain similarities of approach with the verbal research design it complemented. The two had in common the same research problem and the same locality, and it was clear that both would benefit from a certain degree of overlap. The techniques differed as well because of the very different requirements of photographic versus verbal investigation and also because of the distinct kinds of information best communicated by each method.

My wife and I found that it was most efficient to work somewhat separately. Although we were sometimes working with the same individuals, the different sorts of interaction required by our two methods meant that we had to work with them at different times of the day or week. It was often necessary to work with entirely separate participants.

Ducks and duck eggs were the principal items of production in the agricultural industry we investigated. Duck husbandry in the Hulu Sungai region of South Kalimantan has significantly influenced the area's economic development historically and continues to do so today. "Continuing local innovation in traditional management techniques has resulted in high production of eggs, some 67,000,000 a year (1980-1981), and high profit potential for farmers" (Vondal 1984:1). This rural agricultural industry is located in a region with an immense freshwater tropical swamp in an environment usually considered to be uninhabitable and unprofitable by economic development planners (Vondal 1984:1, 13).

In the ethnographic literature, the people of this region are referred to as the Banjar Hulu and are considered a subgroup of the Banjarese-Malay ethnic group predominating in South Kalimantan (Syarifuddin et al. 1981:11). An Islamic people, the Banjar Hulu are widely recognized for their trading prowess (Vondal 1984:15), a skill we found to be essential to the success of the industry.
Small family-operated duck farm enterprises dominate the industry, most managing flocks of 100 birds or less. These farmers produce the nonfertile eggs that are then sold to egg traders at local markets. The traders ship the eggs by boat or truck to the urban centers of Kalimantan for resale. Supplying the farmers with ducks are hatchery specialists and rearing specialists, while feed traders supply them with feed ingredients. A separate group of specialist duck farmers supply the duckling hatcheries with fertile eggs. Thus, the duck and duck-egg industry is characterized by a complex system of specialist groups, including an extensive network of traders who market the products and provide the supplies.

The photography program as initially proposed would, like the core research, take the producer of nonfertile eggs as a focal point of study, designating a sample of such farmers for intensive examination while investigating the related specialists and traders through his central position in the industry. It was apparent at an early stage that these various components of the duck and duck-egg industry are mutually dependent on each other, and that each represents a critical link in the supply-production-distribution system. That the skills of each specialist group of farmers and traders are for the most part mutually exclusive is one of the most remarkable aspects of this industry.

The initial photography plan included as broad subject areas the ecology of the area, land utilization, environmental adaptations, physical constructions like homes and duck cages, material goods and possessions, and the external organization of the farming communities and markets. More specific subjects included farmers' management strategies, production and distribution linkages, labor arrangements, transportation, outside employment, social organizations and marketing, as well as household composition, task distribution, and the cycle of family resources and needs.

\section{Technical Apparatus}

Selection of technical apparatus and materials for this project was based primarily on the need for continuous coverage in all weather and lighting conditions and for equipment that could withstand the damaging effects of water, heat, and humidity in a tropical wetlands environment. Still photography in particular was chosen because of (1) my own expertise in the medium, (2) its relatively low cost, (3) the equipment's overall tolerance to rugged field conditions, (4) the technical simplicity of processing, review, and presentation in the field, and (5) the nature of the research problem. 
processed the photographs myself to limit costs and to maintain consistent image quality and informant privacy. Due to the difficult conditions, processing frequency had to be limited to once every four to five weeks. Total film volume for approximately ten months at the research site was 6,800 frames.

\section{Phases of the Research}

The photography program was expected to proceed in certain distinct stages, based on the researcher's increasing sophistication about the culture and the duck industry, and because of the two different levels of the research problem: the farmers who produce the nonfertile eggs, on the one hand, and the industry specializations and interrelationships, on the other

Reviewing the implementation of the photography program reveals three distinct stages of fieldwork, each characterized by a different research mode: the first five to six weeks may be termed the "entry" phase, the next four months the "expansion" phase, and the last four months the "sample" phase.

Entry. Photographing during the entry phase was characterized primarily by the process of developing a working familiarity with the culture, the geographical area, and the intricacies of the agricultural industry we had come to study; and by the disruptive impact of our presence and my photographing activity. We lived in Desa Satu (a pseudonym), a village approximately three kilometers from the market town of Alabio, and shared the home of a prominent duck farmer and his family. We spent a considerable amount of our time learning the language and certain other basic activities.

At first, use of the camera elicited great excitement and a desire to "be in the picture," especially among children. Adults reacted either by posing or turning away, but generally with amusement. I photographed regardless of response, despite the crowds that always seemed to collect. Apparently there was no specific taboo against photographing, and I wanted to expose my working methods so that curiosity would be satisfied. After the first few weeks, as my purpose became more widely known, I began to limit my photographing to moments when there seemed to be no elicited response. After several weeks of photographing, I began to notice a definite reduction in disruptive response

One photographing behavior I adopted to reduce disruptive response was to minimize the distance between myself and my subject. I accidentally noticed that my initial tendency to stand off a certain distance tended to provoke disruption, while stepping up close seemed to reduce it. Once aware of this relationship, I found that my close-up watching behavior mimicked that of other people who stood and watched. Such close-in observation fostered the use of wide-angle camera lenses, which became standard procedure.

Photographic subject matter of this period reflects an "entry" perspective and consists mainly of the general environments within which more specific photographic coverage was expected to concentrate later: our host village, the nearby markets, and other areas known to be significant to the duck industry. Ecological conditions were clearly significant to the research and very "available" to the entry-phase photographer. These included the rivers and swamps, vegetation, and the seasonal flooding; also, adaptations to ecological conditions such as travel by perahu (small boats that are rowed like canoes) and diesel-powered river launches, homes and duck cages built atop stilts or floating rafts, and elevated wood or bamboo foot paths. I photographed duck cages and pens, herding and feeding ducks, the transportation of the birds and their eggs, and the duck-related market areas. But the photographic coverage was on a general level, lacking specific rele vance, and this is reflected in the assigned significances as well as in the photographs themselves.

Finally, this early phase is characterized by the use of close informants whom we knew well, including our host and a small group of his friends and associates. I was thus able to observe photographically specified events before I became aware of their significance independently. In addition, having these informants overcame the initial problem of unfamiliarity with transportation methods and routes and with the locations of nearby villages, towns, and markets.

Expansion. The beginning of the expansion phase was marked by an incident at the Alabio market when I was able to identify tentatively the activity before me-farmers selling their duck eggs to egg tradersand thus for the first time to observe intensively and without the assistance of an informant-guide. The transition from entry to expansion phase was actually gradual but marked by certain definite incidents like this one. Intensive photographic observation was one of the characteristics of the expansion phase; another was that photographic coverage during this period expanded beyond the limited circle of our host and his associates. I began to search out and photograph activities encountered earlier from the perspective of our duck farmer host and thus expand the range of photographic coverage into the other specializations of the industry, including egg and feed traders, hatchery specialists, and the range of strategies within these two groups. Coverage was expanded geographically as well, as I photographed markets other than Alabio where eggs, ducks, and feed were traded. This represented the first step in understanding the duck and duck-egg-related trade networks and their extent and process 
Events selected for photography became more specifically identified as well as intensively photographed. Rather than photographing "mat weaving," for example (a popular economic activity of women in duck farming households), I photographed identified individuals engaged in specific stages of the process: dyeing the purun reed material, weaving the mats, and finally selling the finished products at the market. Thus, events were identified and photographed in specific contexts rather than as general activities. Similarly, I began photographing several village duck cages that were under construction, tracking the progress over time. I began to make extended contacts on my own, for example, by following a young egg trader of our village and photographing him as he went about his business at the Alabio market, interacting with duck farmers, other egg traders, and riverboat owners engaged to ship the eggs to Banjarmasin, the provincial capital. After a photographic interview with the initial participant, I would follow through with these extended contacts. Through the egg trader, I arranged to accompany his eggs downriver to the resale market in Banjarmasin and photographed the transportation and resale processes. I photographed specific transactions at the markets - a farmer selling his eggs, another purchasing ducklings, a hatchery specialist meeting his fertile egg supplier, etc. - and later interviewed these individuals using the photographs to learn about the transaction method and relationships with the various photographed contacts.

Meanwhile, as the seasons changed-from a pronounced rainy season to a drier-than-usual dry season-I continued photographing the ecological effects, particularly the receding flood waters and the corresponding change in transportation methods, from perahu to taxi pickup trucks and bicycles. My wife and I mapped and I photographically surveyed our village, which we had decided was a suitable location for interview surveys of the core research design and the random sample of duck farming households to be selected later.

Photographic interviews were first conducted during this phase of the research, initially with our host and his friends, and later with a wide variety of individuals. All interviews were conducted in either the local Banjar-Malay dialect or Indonesian, depending on the informant's preference. Most people were surprised at first that they would be able to see the photographs, even though I had assured them they would. The pictures elicited much excitement among family and friends, and many invited me to photograph again whenever I wished to do so. I believe that the photographic feedback was the best way to communicate my purpose. Many of the people knew photographs only as pictures in magazines or as a part of ceremonial events (the area has a history of itinerant photographers, so photographs were familiar objects). Often after the photo-interview, informants would say, "Now I understand why you want to photograph. I would not have wanted you to ask all these questions while I was busy working" (paraphrased and translated). As my working methods became more widely known, the photo-interview in particular became an exceptional source of rapport. Many new participants had already heard about my work and welcomed me and my camera.

In terms of eliciting information, photo-interviewing required some practice on my part. At first my questions were too broad and not connected to the photographs. I noticed that the most useful answers were elicited by questions that were simple and related specifically to the photographic event. I learned to avoid conceptual questions and settled into a pattern of asking many particular questions about particular photographs, pointing to the image as I asked the question. Some informants caught on quickly and provided running narrations of the photographed event, referring to the pictures. I found that most individuals were so accustomed to the activities I photographed that the images served more as points of reference to a specific activity we could discuss than as troughs of information. The images provided a communication link between researcher and participant, a meeting place for our different points of view, and affected the transference of detailed information that would have been very difficult to elicit without the photographs.

Sample. The sample phase was dominated by intensive photography with the randomly selected sample of village duck farmers. From my wife's survey of the duck farming households in our village, ten percent were selected randomly for intensive research. Although we both worked with the same seven households, my wife's method at this point consisted mainly of weekly interviews while my photography was planned around a number of topical constructs. These included:

1. house and duck cage interiors and exteriors (with drawn maps)

2. feeding ducks

3. fishing

4. rice and vegetable cultivation

5. "to the market" series and trade connections

6. buying and selling ducks and ducklings

7. random "short visit" program, for household activity

8. family portraits

9. copying family photographs

All of these objects and activities, with the exception of the last two, were photographed intensively, either by arrangement or by unannounced visits at times when I knew the activity would occur. These plans 
were explained to each family in the beginning, and each agreed to participate.

Like the photography program in general, I began this photographing with the relatively less intimate coverage of the house and duck cage exteriors and interiors and progressed through the work activities and "to the market" series before the much more intimate "short visit" program, which was conducted near the end of the fieldwork period.

The houses and duck cages were photographed with emphases on construction and functional details, and on interior and exterior layout, the latter including the layout of pens in the duck cage and rooms in the house, and also the exterior relationships among these structures and the surrounding environment: the road, the swamp, rice fields, and other houses and duck cages. This created visual links with the earlier village photography survey.

Feeding ducks, fishing, rice and vegetable cultivation, and buying and selling ducks were all photographed by accompanying the household member and photographing his or her behavior throughout the activity. All were followed by informant interviews.

The "to the market" series was somewhat more complicated. It consisted of accompanying the duck farmer to the weekly market and photographing the entire activity throughout the morning, with special emphasis on duck-related market activities. It was at the weekly market that farmers would usually sell their eggs, purchase duck feed ingredients, and arrange the purchase and sale of ducks and ducklings. I selected this activity for photographic coverage for several reasons: (1) marketing skills and arrangements seemed particularly important to successful duck farming, (2) the weekly market trip was a social as well as economic activity, and much pertinent information was traded concerning flock management strategies and market variables, and (3) to make contact with the duck farmer's buyers and suppliers, to photograph these interactions and to target the contacted individuals for extended photographic coverage and nonphotographic interviews. I conducted the nonphotographic interviews for my wife because it was considerably less awkward for me as a man to speak with other men with whom I was not already acquainted.

The purpose of the random "short visit" program was to get a better idea of normative household activity at different times throughout the day. Two weeks of unannounced random visits were slotted to a time chart of the daylight hours, one visit per hour, for each Sample household. All of the Sample participants were informed of this intensive technique before I began, and all agreed to it. When I arrived at each house I announced that it was a "short visit" and proceeded to photograph all apparent household activity, both in the house or duck cage or nearby outside. I randomly chose the time for each visit, and did not visit every day, so as to reduce the possibility of the participants preparing for my visit. The "short visit" program functioned like a fine screen that directed me to photograph activities to which I may not have had access otherwise. The disadvantage of this research technique is that it was implemented only once. The type of household activities in which family members engage is dependent on the season, and so the program helped determine household activity only for the particular time of year.

The family portraits, for which families were encouraged to pose however they wished, and the copied family photographs served as controls for other research photography, both with regard to the formal pose response and as a guide to the community's use of photographs prior to our arrival. Additionally, the family photographs - and almost every household possessed at least a few-comprised a visual family history of important events. Most of the photographs were made in a studio, by itinerant photographers, or by relatively wealthy relatives who owned pocket cameras. The ceremonies and events documented in the family photographs included weddings, trips to the city, and the religious pilgrimage to Mecca. The photographed individuals included family members as well as friends and relatives.

Extended photographic coverage continued throughout the sample phase via contacts I made independently as well as through the Sample households. Some of the extended coverage was repetitive and concerned the same kinds of subject matter I had photographed earlier, while some was entirely new. The latter included fertile egg suppliers, their special flock management techniques, and their connections to the hatchery specialists who purchased the eggs; the sago palm trade (one of the ingredients of duck feed); detailed coverage of the duckling hatchery process; an Islamic madrasa school where one of the Sample informants was employed as a teacher; a women's Koran study meeting at a village prayer house; and Friday congregation at a large mosque in Amuntai, the regency capital.

I photographed many social and religious affairs during both the expansion and sample phases, including weddings, holiday celebrations, a child-naming ceremony, graduation from grade school, and the construction of a new village mosque. Some of these events I was specifically requested to photograph, while for others I was encouraged to do so by the local residents because, they said, these things are important aspects of community life. Such insights and encouragement were very valuable, and served to enrich the photographic collection and our understanding of social life in the community. 


\section{Conclusions}

My concern here has been to devise a method of photographic data generation that in some way includes the influence of the observation process, because, as Worth pointed out (1980:19), "primary photographic data are also a structured event." The validity of such a method, like that of all descriptive systems, would rest on "the strength of the epistemological system which underlies the description" (Ruby 1977:235). The photographic research method represents an attempt to create a validative system of visual description based on the methodology that produces the images and associated data. The epistemological mechanism of the method consists primarily of connecting the images to the context of observation through an identification of the photographic event, and secondarily, of establishing a system of observation based on hypotheses of significance.

The method acknowledges the context of observation by means of the "photographic event" concept, while observation itself is based on a significance format that permits the photographer-researcher to observe and photograph freely while maintaining the a priori hypothesis orientation that the investigative mode requires. This allows the image producer to be responsive to the structure of the event he is photographing. Sandall (1972:193) and Asch et al.

(1973:180), among others, have rightfully placed highest priority on maintaining the integrity and structure of events in the filmic record. But as Sandall (1972:193) notes, observation is not antithetical to theories and goals.

The significance statement, assigned before photographing, constitutes an apriority and justifies the selection of the event for observation. Den Hollander (1967:6-8) has argued that observation in a social science study is concerned with an already-established "conceptual framework" that selectively sensitizes the observer's perception, and that therefore observation itself is a process of a priori reasoning. Photography is merely an extension of observation, and both require exceptional selectivity based on the perceived significance of events.

Finally, this method of photographic observation requires a very significant change in the role of the image producer. Of the set of explicit circumstances comprising the context of the photographic event, the photographer's presence is clearly primary. As the circumstances of the photographic interaction are made explicit, the photographer no longer assumes the traditional "omniscient observer" role, but begins to appear more like a participant than an observer. The concept of image producer as social interactant is considered central to the photographic research method; and the act of photographing is considered a communication event in which the photographer and the informant are mutual participants. The communicating relationship is enhanced further by informant access to the photographs and the feedback response. MacDougall (1975:119) suggests that such mutual participation in filmmaking represents the basis for a new "participatory cinema" that bears witness to the "event of the film," while Sandall (1972:196) warns that "the mutual claims of the identities on either side of the camera must be brought more nearly into balance if either is in the long run to survive."

The photographic research method is designed to include in the process of research individuals from both sides of the camera. By doing so, a communication system is established and the photographic record is critically enhanced. Rouch's (1975:100) concept of "shared anthropology" is particularly appropriate for anthropological film and photography, where the camera is too often an instrument of acquisition and division. The value of photography in anthropology is not that it can record "objective reality," but that it offers a medium of communication between the researcher and the native participant, and between their respective communities. 


\section{Examples from the Photographic Record}
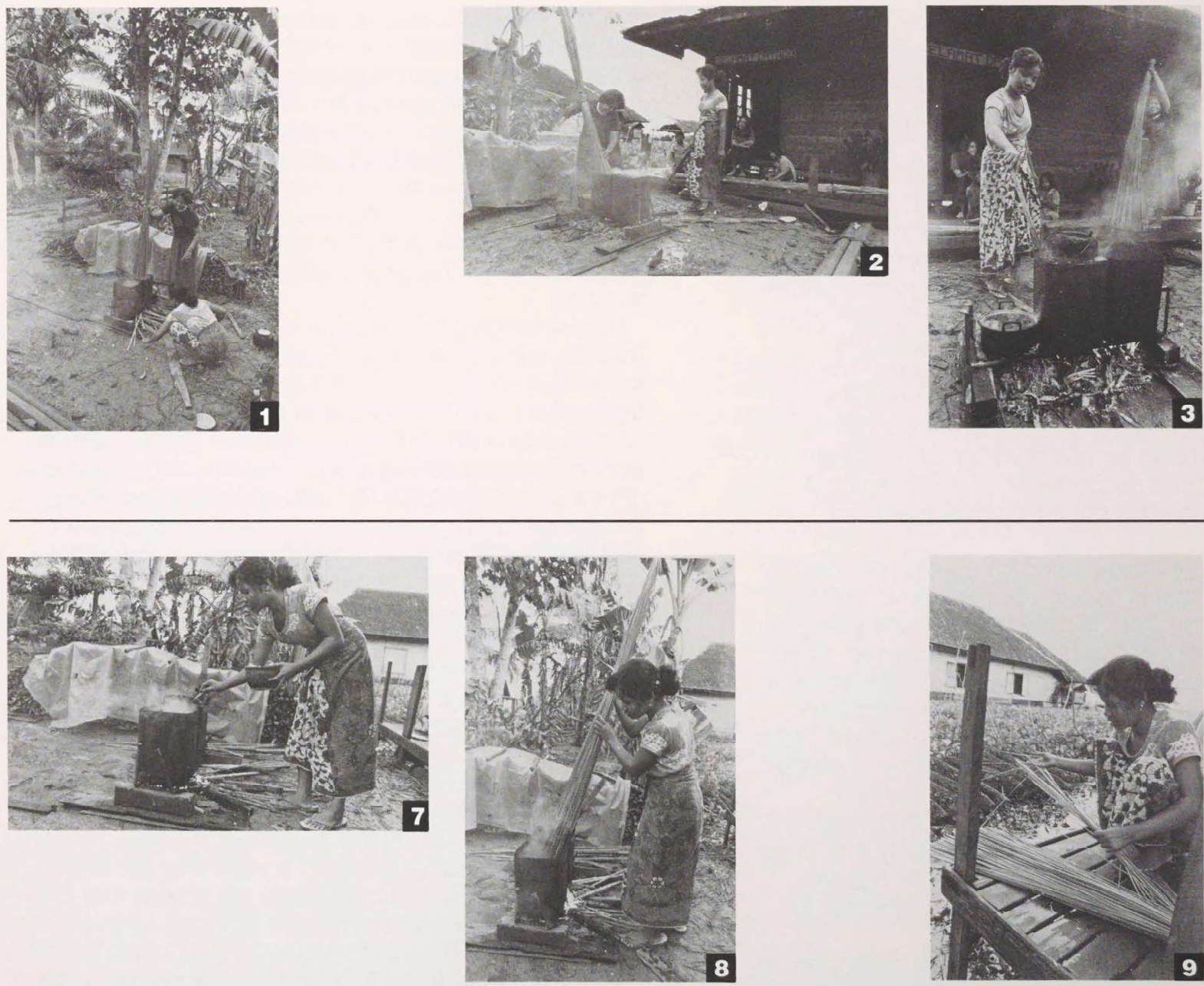

Figure 2 Two Eldest Daughters of the Nawari Household Dye Purun Mat Material

\section{Introduction}

This is an edited version of the original analysis set consisting of thirty-six photographs. Nawari and his family were our hosts, and we lived in this house at the time. In the six weeks since our arrival, we had become relatively comfortable with Nawari's family and they with us.

\section{File Data}

Analysis set: 056

Date: February 7, 1982

Images: 27:1-36

Point/Boundary sets: two

\section{Operational Significance}

Photographs 1-10 (27:1-29). Point: purun dyeing activity in front of the Nawari house. Step-by-step process centered on the tins of dye. Boundaries: area between the house and road directly in front of the house-front platform.

Photographs 11-12 (27:30-36). Point: rinsing and hanging dyed purun at the rear of the Nawari house. Boundaries: handling of the dyed purun bundles.

\section{Written Annotation}

Mat weaving is a very important economic activity in the village. Woven primarily by the women and girls, mats provide a small income that is usually supplemental to a greater income source, such as duck farming. We know of some women who subsist solely on mat production, however. Among duck farming households such as Nawari's, we are interested in sources of supplemental income and their relationship to the variable economics of duck husbandry.

Immediately after breakfast this morning, I noticed Saudah and Sonyah in front of the house preparing to dye the reed material ( $p u-$ run) used to weave mats. I thought it a good opportunity to photograph this step in the mat-making process, so I loaded a camera with film and returned. I began photographing as soon as I reached the front platform. The response from the girls was much giggling 

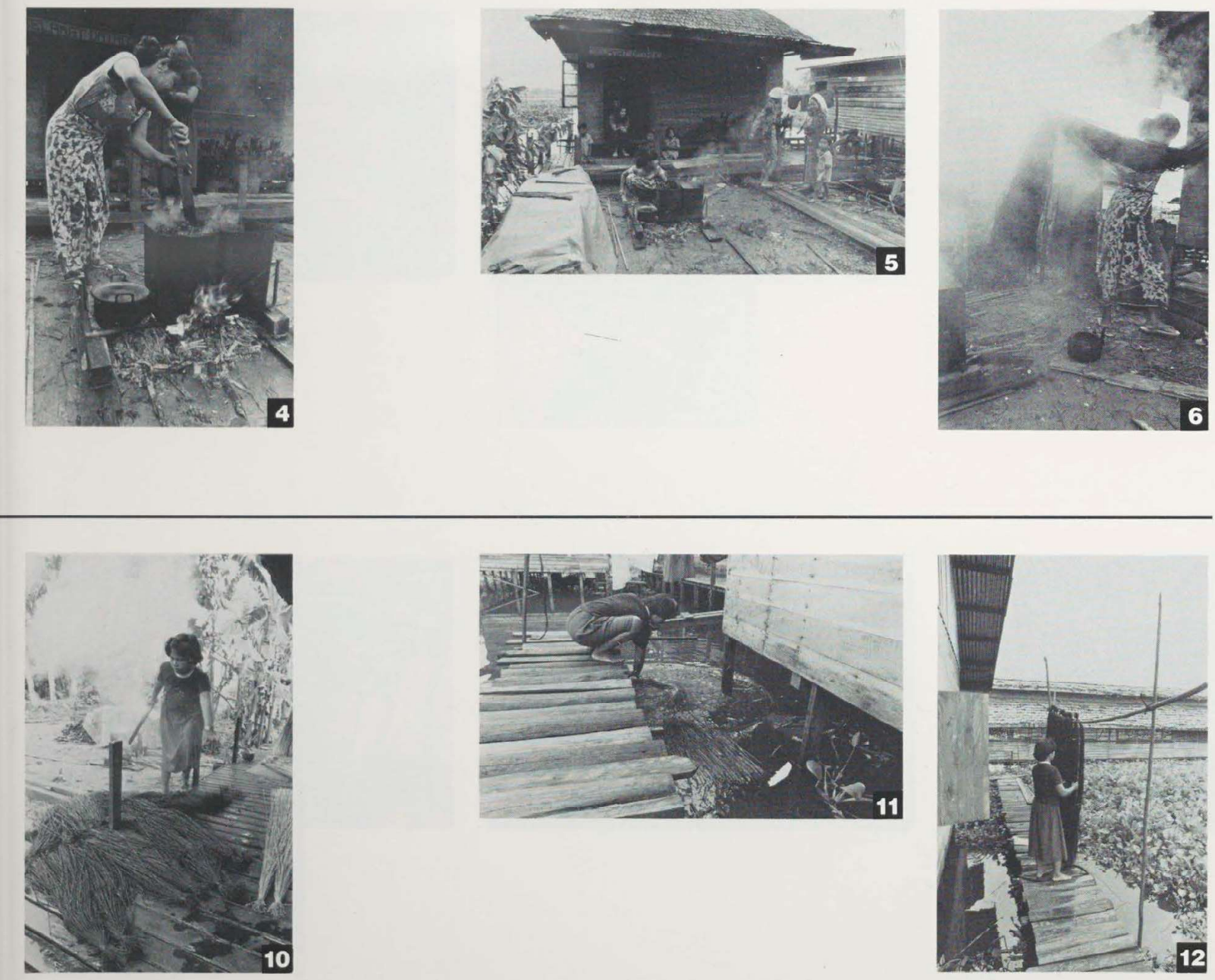

and shy laughter, but they did not stop what they were doing. The show of camera recognition did not concern me; what was important was that the activity continued relatively undisturbed. After the first few minutes they seemed more at ease with my presence, but they continued talking to Patricia, who was watching from the doorstep, telling her that my photographing made them feel "like movie stars." My impression was that they were engaged in a well-practiced activity that remained essentially unaffected by my presence.

I had not seen this process before, except in passing, so I did not know what to expect. The girls' activity seemed to center on the tins of dye. I photographed broadly everything they did. The photography was repetitive, as I realized that approximately the same steps were being repeated for each bundle of purun. As I photographed, two women came by, both neighbors who live just down the road from us. One walked around the side platform to the rear of the house, and the other stood on the front platform and watched. The latter held a young child in her arms while a little boy stood alongside grasping her sarong.

The dyeing process consists of several discernible steps. The undyed purun, a tawny color and somewhat stiff, was bundled and tied at one end of the platform, and a husklike shell was shucked from the thicker untied ends of the reeds. The shucking was done at the far left side of the house platform, the husks dropping into the swamp below. The bundle of purun was then placed into one of the two tins of dye, the untied end first, and pushed into the tin as the reeds softened. A wooden stick was used to submerge the last bit of purun in the steaming dye. Sometimes a pot was placed on top, perhaps to keep the purun submerged. The second tin of dye was tended as the first "cooked." As each bundle was removed, it was placed on the house platform to the right. Intermittently, more wood was added to the fire and spoonfuls of powdered dye were added to the tins from an earthenware crock. As the dyed bundles accumulated on the platform, Sonyah began carrying them to the rear of the house via the side platform, where she hung them from a horizontal pole beside the walkway leading back to the duck cages. Each bundle was rinsed in the swamp water beside the walkway before being hung on the pole, presumably to dry.

I stopped photographing when it seemed certain that only repetitive actions were occurring. I waited to make sure that nothing new was happening before leaving the scene. 

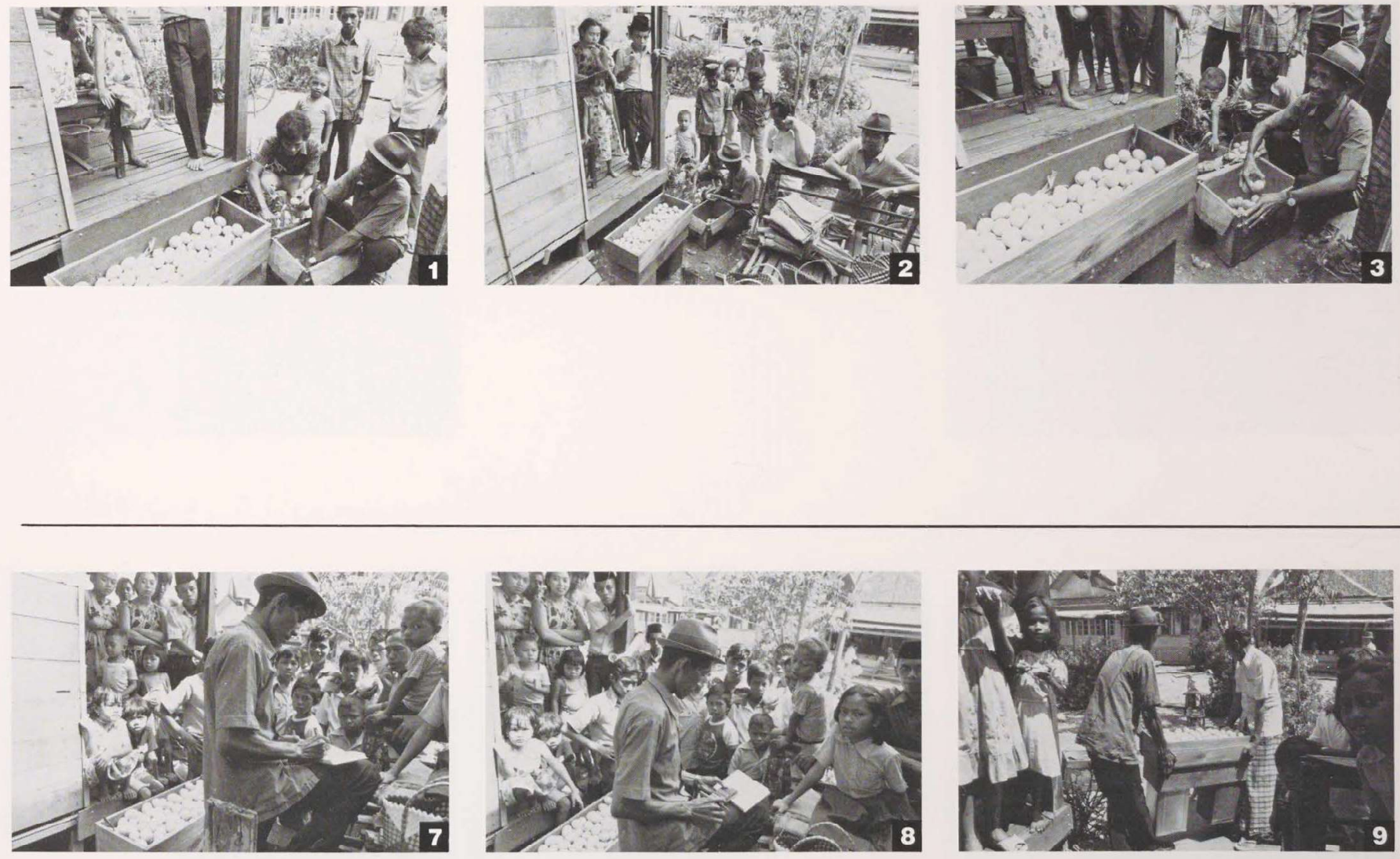

Figure 3 Hilmi Meets His Fertile Egg Supplier in Amuntai

\section{Introduction}

This is an edited version of the original analysis set consisting of eighteen photographs. Hilmi is a prominent duckling hatchery specialist with whom I had spoken several times. We had lived in the area for a total of four months at this time.

\section{File Data}

Analysis set: 120

Date: June 10, 1982

Images: 47:19-36

Point/Boundary sets: one

\section{Operational Significance}

Photographs 1-12 (47:19-36). Point: interaction and process as Hilmi meets his fertile egg supplier at the Amuntai market.

Boundaries: immediate area; transaction procedures.

\section{Written Annotation}

I was walking down the street of the duck market in Amuntai when Hilmi waved me over and invited me to sit down beside him. Apparently, he had been chatting with two other men when he saw me. It was almost midday and the duck market had wound down for the day. I had already met Hilmi and found him to be exceptionally friendly. I went over and sat down. We chatted for awhile.

Then a man walked up with a cardboard box, and Hilmi said to me as he got up that this man brought his eggs and so Hilmi had to "attend to business." I asked if they were fertile eggs for his hatchery, and he answered yes. It seemed I had stumbled upon a transaction between two different industry specialists: a hatchery operator and a fertile egg producer. I photographed the "connection" between the two. Though I did not ask permission to photograph, I walked over with my camera, obviously ready to

photograph, and Hilmi nodded his approval. As I began photographing, a small crowd formed around the two men and watched. 

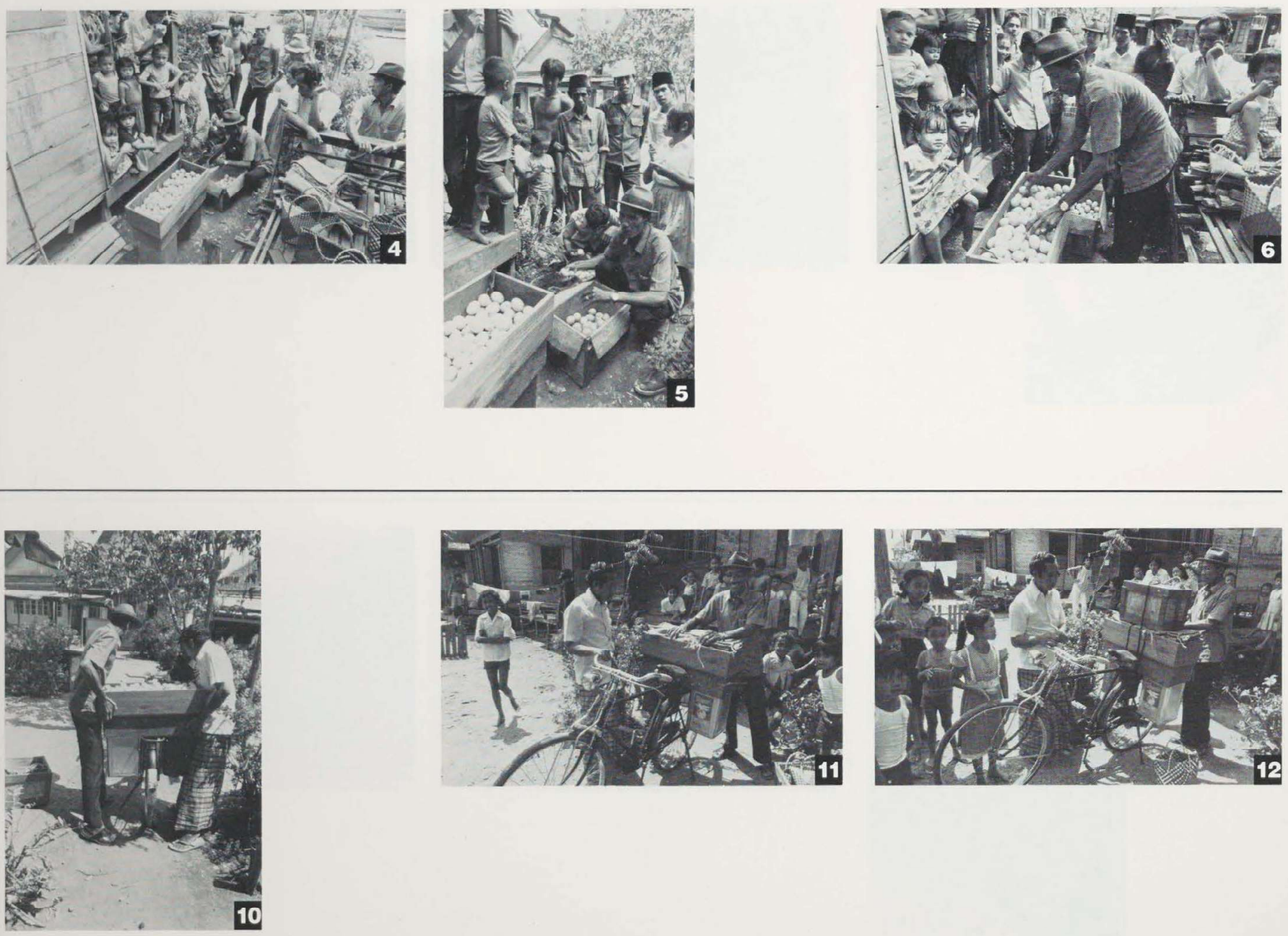

Hilmi worked in a tight spot between the front platforms of two houses. The man who had brought the eggs carried them in cardboard boxes, and Hilmi and an unidentified man counted out the eggs and transferred them to a bicycle carrier, which was at that point detached from the bicycle. While photographing, I realized that I had made two unqualified assumptions about this event: that it was a transaction, that is, a sale; and that the fertile egg producer was present. (He was, I found out at the photo-interview: second from the right at the top of photo 1.) It was still hard to tell for sure even halfway through the event. I continued photographing as the bicycle carrier was loaded and another wooden box was filled with eggs. Hilmi made entries into a notebook and did some calculations on a pocket calculator, as the crowd continued to stare at us.

Hilmi and a man in a sarong carried the egg crate to the bicycle and lashed it in place with rubber cords. Hilmi told me as he did this that he had built the egg carrier himself, especially for eggs. The smaller wooden crate was tied on top of the larger one. As Hilmi pedaled away on his loaded bicycle, I said that I'd call on him when the photographs were ready. 

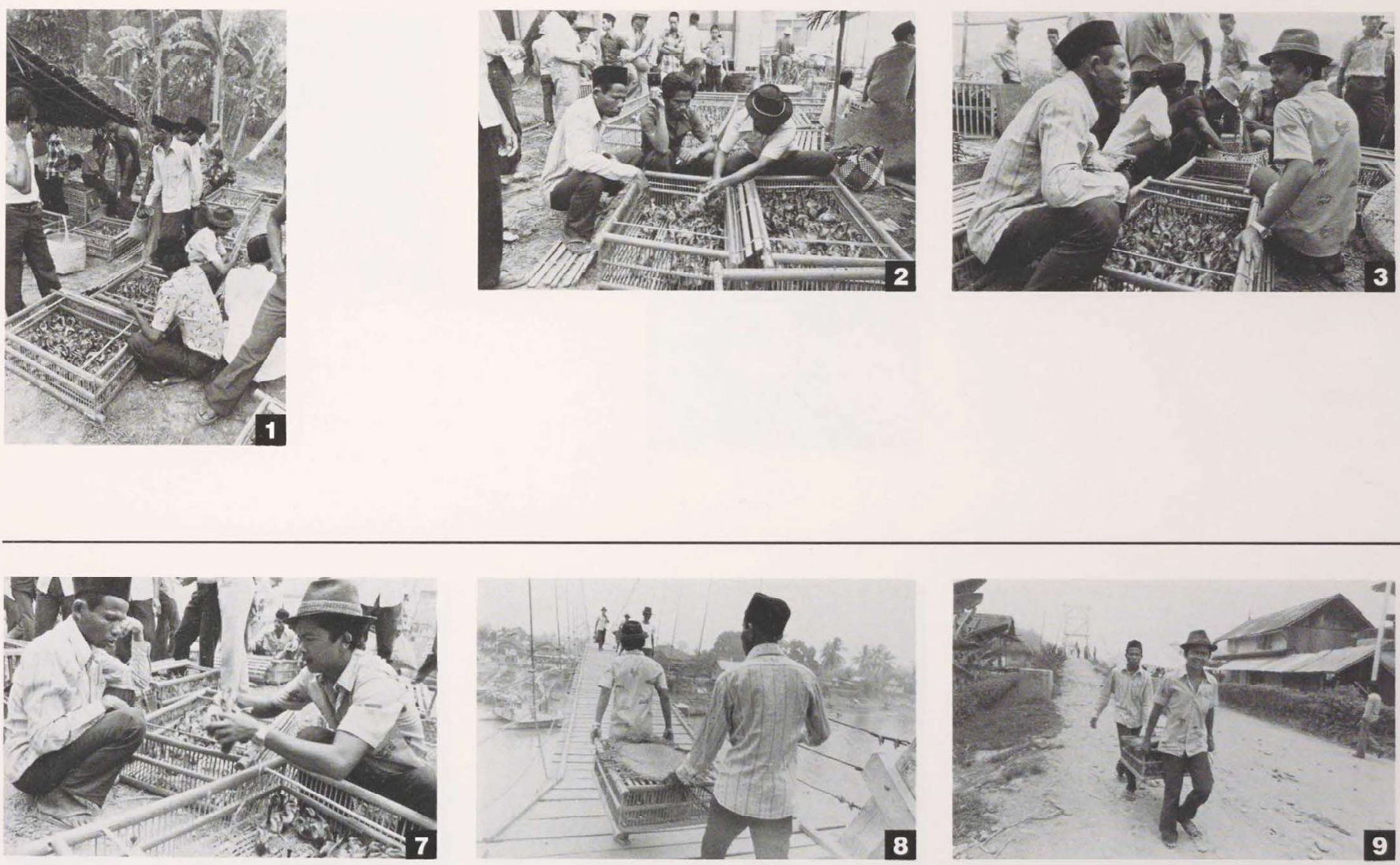

Figure 4 Pii Purchases Ducklings at the Alabio Market

\section{Introduction}

This is an edited version of a group of thirty-eight photographs constituting a subset of the analysis set, "To the Market with Pii." Pii's was one of the seven randomly selected duck farming households chosen for intensive study, and the analysis set that includes these photographs is part of the "to the market" series conducted with each of the sample households.

\section{File Data}

Analysis set: 251

Date: October 6, 1982

Images: $134: 9-35$ and $135: 26-36$

Point/Boundary sets: four
Operational Significance

Photographs 1-7 (134:9-35). Point: Pii's activities as he looks for ducklings to purchase at the Alabio duck market. Boundary: tracking series, Pii.

Photographs 8-9 (135:26-29). Point: Pii and Dubran carry the farmer's ducklings across the footbridge spanning the river.

Boundary: tracking series, Pii.

Photographs 10-11 (135:30-32). Point: Pii discusses his duckling purchase with several men. Boundaries: the individuals paying attention to the discussion.

Photograph 12 (135:33-36). Point: a cage of ducklings is removed from the roof of the taxi pickup truck in which Pii is returning home; Desa Satu. Boundaries: the road and the truck. 

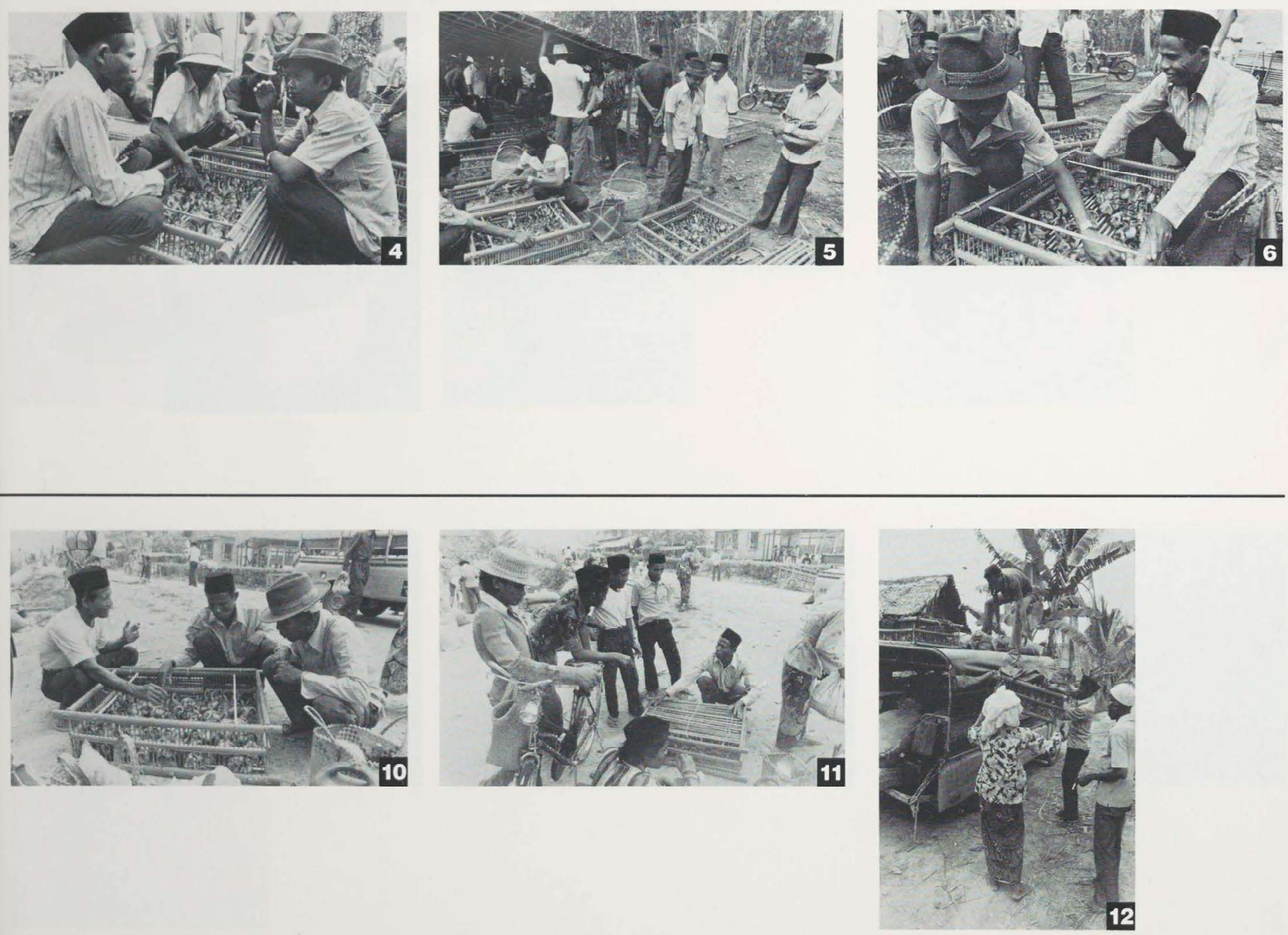

\section{Written Annotation}

I accompanied Pii to the Alabio market this morning as part of the "to the market" series, not knowing that he would be looking for ducklings this week. After selling his 617 eggs for the week, Pii informed me that he was going over to the duck market to look for ducklings. This surprised me because I knew that he had just bought ducklings the week before. Arriving at the duck market at 9:30, Pii looked around a bit and talked with only one other duckling seller before settling on Dubran, a hatchery operator. The two men had a long discussion over the duckling cage which resulted by 10:10 in Pii buying 100 four-day-old female ducklings for Rp 500 (U.S. \$0.72) each, on personal credit.

Pii explained to me later that the 250 ducklings he purchased last week were from the same dealer, and that they too were on credit. He said that Dubran had not been willing to extend him credit for more than 250 ducklings last week. But this week, because Pii made a payment toward the initial credit, Dubran agreed to an additional 100 birds. Pii said that he thought Dubran agreed to today's sale because the duckling market was down, as evidenced by the price reduction from last week's Rp 550 to this week's Rp 500 per bird. Pii told me that he has known Dubran for many years, and that Dubran often sells ducklings to farmers from Pii's section of the village.

When the duckling sale was settled, Dubran counted out the birds and Pii left the cage with the dealer. After a stop at a tea shop, we walked through the general market where Pii bought rice and various food items. At 11:50, I followed as Pii and Dubran carried the duckling cage across the river via the footbridge to the taxi area. While waiting for an available taxi pickup, Pii discussed his duckling purchase with several men, one of whom was Nawari, the head of the household in which Patricia and I live. I left Pii at this point because I had other business to attend to in Alabio before returning to the village.

Later, I got a ride home on the back of a friend's motorcycle, and as we entered Desa Satu we passed a taxi pickup truck in which I thought I recognized Pii. I walked down to meet the truck and arrived just as a cage full of ducklings was removed from the roof. These were not Pii's, however, but Mama Mahidi's, who was standing beside the truck. Mama Mahidi is a member of another of our seven Sample households. 

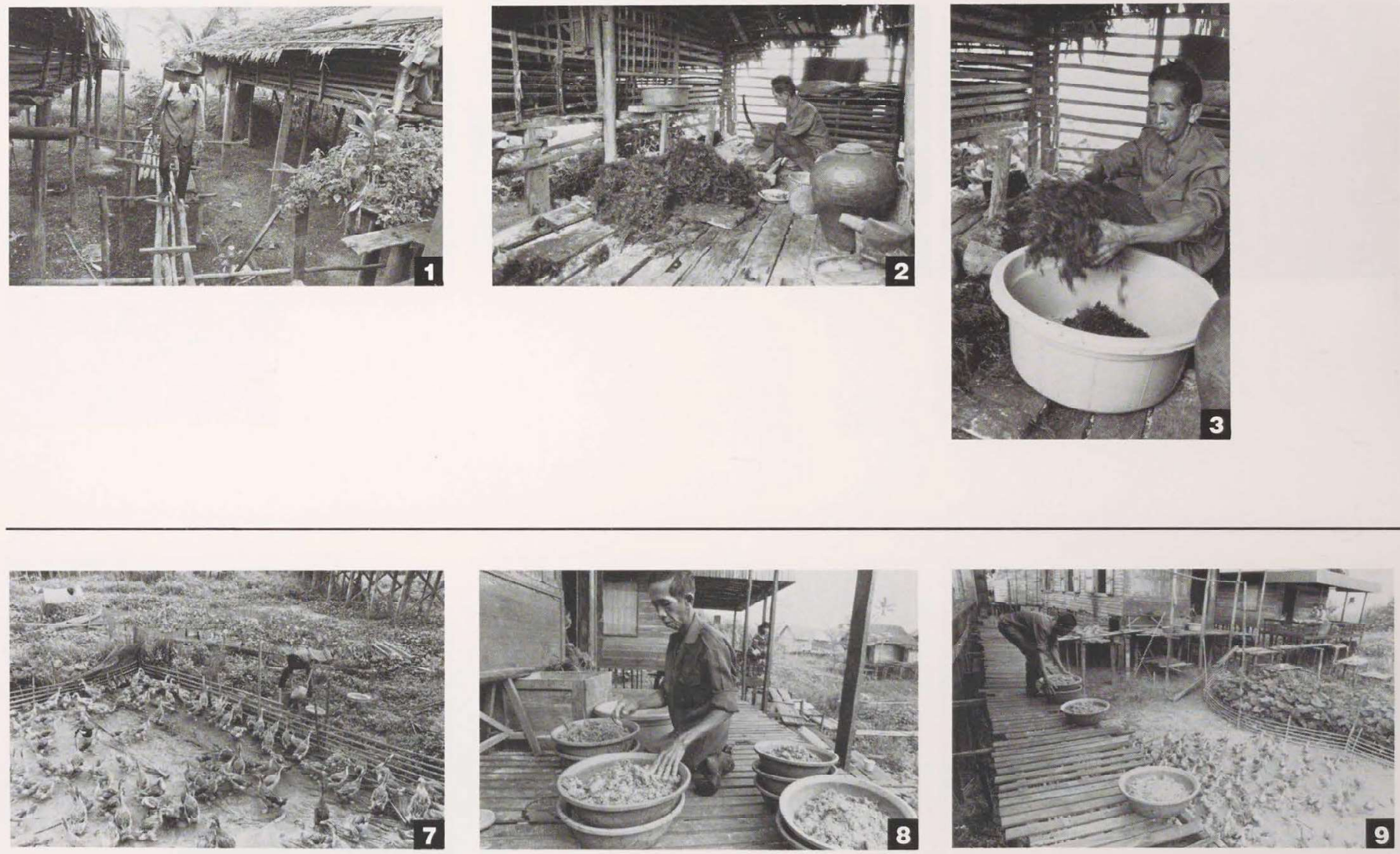

Figure 5 Nahli Feeds His Four-Month-Old Ducklings, Desa Satu

\section{Introduction}

This is an edited version of a group of fifty-eight photographs constituting a subset of the analysis set, "Feeding Ducks, A.M., Nahli Household." Nahli's was one of seven randomly selected duck farming households chosen for intensive study, and the analysis set that includes these photographs is part of the "feeding ducks" series conducted with each of the Sample households.

File Data

Analysis set: 275

Date: October 19, 1982

Images: 153:4-36 and 154:1-25

Point/Boundary sets: four
Operational Significance

Photograph 1(153:4-5). Point: Nahli returns from the swamp with collected ganggung. Boundaries: the two duck cages and the elevated walkway.

Photographs 2-3 (153: 6-26). Point: Nahli prepares duckling feed on the rear platform of his house. Boundaries: the house, right; the duck cage, left.

Photographs 4-6 (153:27-36 and 154:1-3). Point: Nahli prepares duckling feed on the front platform of his house. Boundaries: the platform and the front wall of the house.

Photographs 7-12 (154:4-25). Point: Nahli distributes feed among his ducklings penned below and in front of the house. Boundaries: Nahli's house, the two adjacent houses, the road, and the bridge in front of all three buildings. 

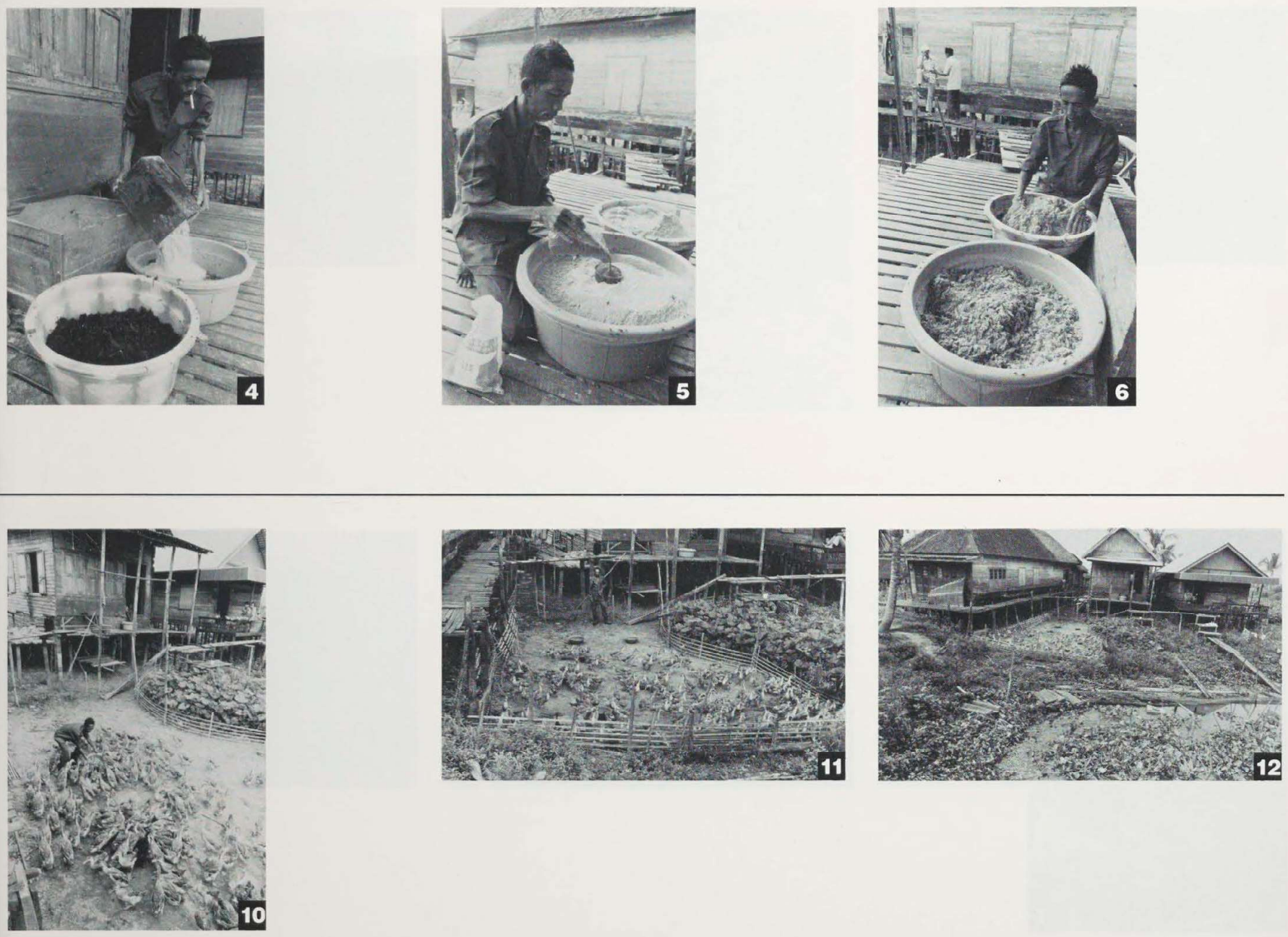

\section{Written Annotation}

I arrived unannounced at Nahli's house at 6:40 A.M. to photograph the feeding of the family's ducks. Between $6: 40$ and 7:00 I photographed as Nahli's sister-in-law prepared the feed mixture and fed the egg-laying ducks, which are housed in a cage behind the house. Just as I arrived, Nahli left to collect ganggung (a variety of swamp plant) from the swamp. The layer ducks were fed by 7:00 when Nahli returned with his backpack basket filled with ganggung. I photographed as he chopped the ganggung for the ducklings' feed. Nahli used a long knife and chopped on a curved wooden trough located on the rear platform between the house and the layer duck cage. Meanwhile I noticed that Nahli's wife was preparing coffee and breakfast pastry.

Nahli and I sat on the mat-covered floor of the dapur (where the cooking is done), had breakfast, and talked. Although my initial impression was that the coffee and pastry had been prepared because I was there, Nahli told me, as if reading my thoughts, that he always has breakfast after collecting the ganggung in the morning. $\mathrm{He}$ added that he prefers coffee in the morning rather than tea, the more popular drink.
Soon it was back to feeding the ducklings. Nahli carried the two large plastic tubs of chopped ganggung through the house to the front platform, where he mixed it with dedak (ground rice bran) from a storage box. Then he added small measured amounts of konsentrat and Vita-Mineral, processed vitamin and mineral supplements, to each tub. After mixing the ingredients of each tub with his hands, he collected the feed bowls from the penned area in front of the house. By this time, the ducklings knew they were going to be fed and had come out from under the house and were milling about expectantly. Nahli distributed the feed among nine bowls on the front platform and finally placed the bowls on the ground in the duckling pen. He told me that the bowls should be spaced evenly so that each duckling consumes about the same amount of feed. I photographed from an adjacent walkway and then from the road, completing the series with wide views of the nearby environment: the two adjacent houses and the stream that runs in front of the duckling pen. When all the feed was consumed, the whole flock of ducklings, as if on cue, returned to the part of their pen that is below the house. The time was $8: 45$ 

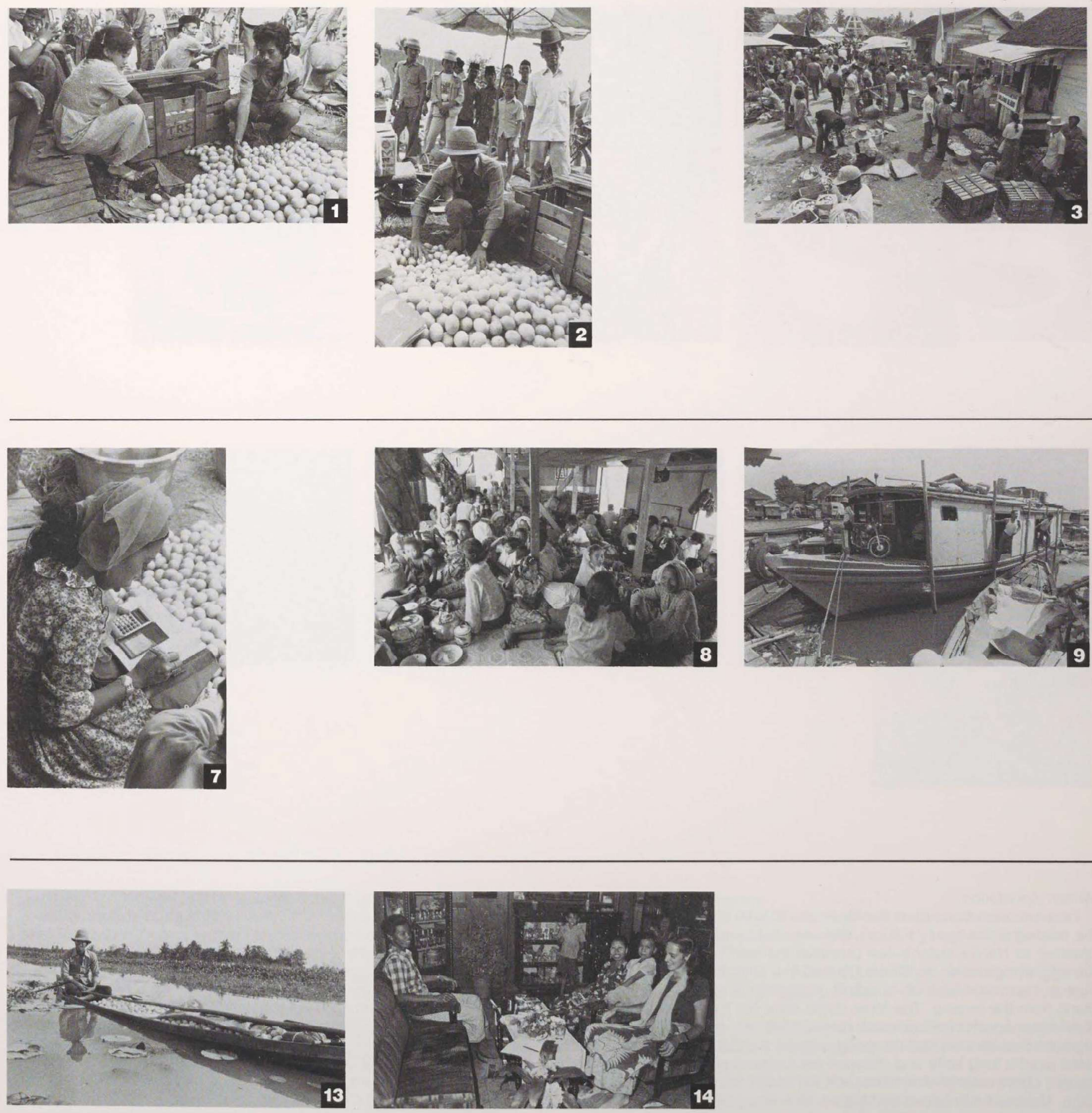

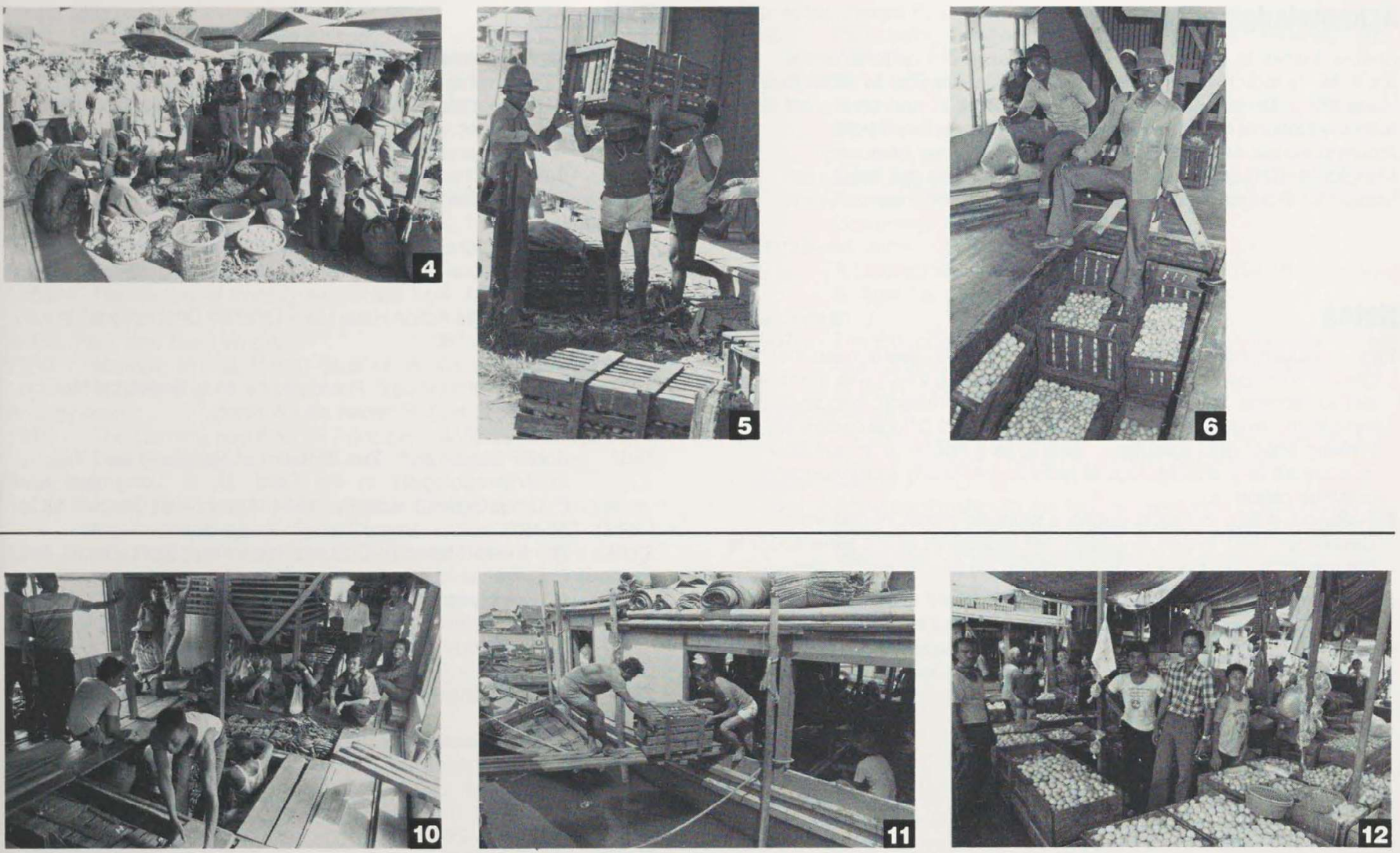

\section{Figure 6 Tarsji, Desa Satu Egg Trader}

\section{Introduction}

This set of photographs was assembled to illustrate connective context. Events are selected for coverage based on their connections with other specific and previously photographed events. These photographs, selected from a total of 210 frames, are related in two significant ways: all concern the same egg trader and the various activities of his profession; as a set, they represent the extended contacts made through this individual with other components of the industry. Tarsji was a young egg trader from our village of Desa Satu whom I met one day at the Alabio market.

\section{File Data}

Photos 1-3: analysis set 053 (40 images), February 3, 1982 Photo 4-6: analysis set 146 (87 images), June 23, 1982

Photo 7: analysis set 229 (7 images), September 15, 1982

Photos 8-11: analysis set 190 (65 images), August 12, 1982

Photo 12: analysis set 191 (4 images), August 12, 1982

Photo 13: analysis set 100 (5 images), March 9, 1982

Photo 14: analysis set 202 (2 images), August 28, 1982

\section{About the Photographs}

Photographs $1-3$. This was the first day I began observing and photographing intensively at the Alabio market. I stood at what I guessed to be the egg market and watched the jumble of activity before me. I photographed several broad overviews of the area (3) before settling on "people handling eggs" as suitable subject matter I had not yet met Tarsji when I photographed him (2) and his wife and assistant (1) packing egg crates. Later, he asked if he could have one of the photographs, and this is how we met.

Photographs 4-6. I had arranged with Tarsji to photographically track his activities throughout the market day at Alabio, from 8:00 A.M. to 12:00 P.M. During these four hours I attempted to photograph his every activity and those of his wife and assistants. I kept track of their trading area (4) as they purchased eggs from farmers, photographed Tarsji as he walked about discussing egg prices and other market variables with fellow egg traders, and later photographed as the egg crates were loaded onto a riverboat for shipment to Banjarmasin (5). At the end of the market day Tarsji decided to pose with his eggs on the riverboat, the egg crates in the hold below floor level (6). 


\section{Acknowledgments}

Special thanks to Dr. Steven Feld for his excellent editorial assistance. My research was funded in part by Cathay Pacific Airways, Hong Kong. Dr. Vondal's research was funded in part by a grant from the National Science Foundation and by Cathay Pacific Airways. Indonesian sponsors included Universitas Lambung Mangkarat, Banjarmasin, Kalimantan Selatan, and the Indonesian Institute of Sciences, Lembaga IImu Penelitian Indonesia, Jakarta.

\section{Notes}

1 By "culturally conventional patterns" I mean the assumption that photographs possess certain inherent qualities that make them objective records, documentary fact, artistic expression, and so on. I have in my experience moved through several different ways of thinking about photography, originally as a hobby, then as documentary art and archaeological record, and finally as ethnographic communication.

2 Fieldwork was conducted during a fourteen-month period from December 1981 to January 1983, ten months of which were spent at the research site. For a complete report on this research, see Vondal (1984).

\section{References}

- Asch, Timothy, John Marshall, and Peter Spier

1973 Ethnographic Film: Structure and Function. In Annual Review of Anthropology, vol. 2. Pp. 179-187. Palo Alto: Annual Reviews Inc.

- Bateson, Gregory, and Margaret Mead

1942 Balinese Character: A Photographic Analysis. New York: New York Academy of Sciences.

- Byers, Paul

1964 Still Photography in the Systematic Recording and Analysis of Behavioral Data. Human Organization 23:78-84.

- Cody, Arthur B.

1967 Can a Single Action Have Many Different Descriptions? Inquiry 10(2):164-180

- Collier, John, Jr.

1967 Visual Anthropology: Photography as a Research Method. New York: Holt, Rinehart and Winston.

- den Hollander, A. N. J.

1967 Social Description: The Problem of Reliability and Validity. In Anthropologists in the Field. D. G. Jongmans and P. C. W. Gutkind, eds. Pp. 1-34. Assen: Van Gorcum \& Co.

- Geertz, Clifford

1973 The Interpretation of Cultures. New York: Basic Books, Inc.

- Goldschmidt, Walter

1972 An Ethnography of Encounters: A Methodology for the Inquiry into the Relation between the Individual and Society. Current Anthropology 13(1):59-78.

- Heider, Karl G.

1976 Ethnographic Film. Austin: University of Texas Press.

- Jacknis, Ira

1984 Franz Boas and Photography. Studies in Visual Communication 10(1):2-60.

- Jarvie, I. C

1975 Epistle to the Anthropologists. American Anthropologist $77(2): 253-266$

- MacDougall, David

1975 Beyond Observational Cinema In Principles of Visua Anthropology. Paul Hockings, ed. Pp. 109-124. The Hague: Mouton

\section{continued from page 51}

Photograph 7. I was photographing at the Alabio market with another participant when I noticed Tarsji's wife at their usual egg trading spot, apparently doing the bookkeeping. I watched and photographed as she did the calculations on a pocket calculator and made notations in a notebook. In the record book were recorded egg purchases and prices paid in Alabio and other markets, as well as the volume sold and price received for eggs at the Banjarmasin resale market on Thursdays and Fridays.

Photographs 8-12. Having made contact with the riverboat owners during Tarsji's earlier egg shipment, I arranged to accompany his eggs one week on the twenty-four-hour riverboat trip downriver to Banjarmasin. This particular riverboat carried both cargo and passengers $(8,9)$. Most of the egg crates were stored below the floorboards in the hold, but some were stacked in the main passenger area $(8,10)$. When we arrived at "Lima" market in Banjarmasin, I photographed as the egg crates were unloaded and carried to the egg market nearby (11). I photographed Tarsji and his helpers at their selling stall (12). Most of the eggs sold here were sold in small quantities, at a markup over the Alabio price, to individuals for home or restaurant consumption.
Photograph 13. Patricia and I were returning to our house in Desa Satu by perahu when we ran into Tarsji on the swamp. His perahu was loaded with duck eggs. He explained that he had just purchased the eggs from several farmers in a nearby village and would bring them to the Alabio market the next day to ship to Banjarmasin. $\mathrm{He}$ explained that because of the recent greater-than-usual amount of flooding, it would be difficult for farmers in that particular village to get the eggs to market, and thus they were willing to sell to him at a lower price.

Photograph 14. Patricia and I went to Tarsji's house in Desa Satu to conduct a photo-interview. We sat in the front room and began the interview as his wife brought out tea and corn for all of us. The tape-recorded interview lasted more than an hour, after which we chatted and I photographed. Tarsji is seated at left, his wife center, and Patricia is at right. 
- Mead, Margaret

1962 National Character. In Anthropology Today: Selections. Sol Tax, ed. Pp. 396-421. Chicago: University of Chicago Press.

1970 The Art and Technology of Field Work. In A Handbook of Method in Cultural Anthropology. Raoul Naroll and Ronald Cohen, eds. Pp. 246-265. Garden City, N.Y.: Natural History Press.

- Myerhoff, Barbara, and Jay Ruby

1982 Introduction. In A Crack in the Mirror: Reflexive Perspectives in Anthropology. Jay Ruby, ed. Pp. 1 35. Philadelphia: University of Pennsylvania Press.

- Newhall, Beaumont

1964 The History of Photography. New York: Museum of Modern Art.

- Rotha, Paul, and Basil Wright

1980 Nanook of the North. Studies in Visual Communication 6(2):33-60.

- Rouch, Jean

1975 The Camera and Man. In Principles of Visual Anthropology Paul Hockings, ed. Pp. 83-102. The Hague: Mouton.

- Ruby, Jay

1975 Is an Ethnographic Film a Filmic Ethnography? Studies in the Anthropology of Visual Communication 2(2):104-111.

1976 In a Pic's Eye: Interpretive Strategies for Deriving Significance and Meaning from Photographs. Afterimage 3(9):5-7.

1977 Review of Karl Heider's Ethnographic Film. Journal of Communication 27(3):234-236.

- Salamone, Frank A.

1979 Epistemological Implications of Fieldwork and Their Consequences. American Anthropologist 81(1):46-60.

- Sandall, Roger

1972 Observation and Identity. Sight and Sound 41(4):192-196.

- Sekula, Allan

1975 On the Invention of Photographic Meaning. Artforum 13(5):36-45.

- Snyder, Joel, and Neil W. Allen

1976 Photography, Vision and Representation. Afterimage 3(7):8-13.

- Sorenson, E Richard

1967 A Research Film Program in the Study of Changing Man. Current Anthropology 8(5):443-469

1968 The Retrieval of Data from Changing Culture: A Strategy for Developing Research Documents for Continued Study. Anthropological Quarterly 41:177-186.
- Spradley, James P

1980 Participant Observation. New York: Holt, Rinehart and Winston

- Syarifuddin, M. Idwar Saleh, and M. Nasai

1981 Sistim Kesatuan Hidup Setempat Daerah Kalimantan Selatan. Banjarmasin, Indonesia: Departemen Pendidikan dan Kebudayaan. Cited in Entrepreneurship in an Indonesian Duck Egg Industry: A Case of Successful Rural Development, Patricia J. Vondal. Unpublished Ph.D. dissertation, Rutgers University, 1984

- Szarkowski, John

1975 A Different Kind of Art. The New York Times 124:16 +, Section 6. April 13

- van Velsen, $\lrcorner$

1967 The Extended-Case Method and Situational Analysis. In The Craft of Social Anthropology. A. L. Epstein, ed. Pp. 129-149. London: Tavistock Publications.

- Vayda, Andrew P.

1983 Progressive Contextualization: Methods for Research in Human Ecology. Human Ecology 11(3):265-281

- Vondal, Patricia J.

1984 Entrepreneurship in an Indonesian Duck Egg Industry: A Case of Successful Rural Development. Unpublished Ph.D. dissertation, Rutgers University.

- Worth, Sol

1980 Margaret Mead and the Shift from "Visual Anthropology" to the "Anthropology of Visual Communication." Studies in Visual Communication 6(1):15-22.

1982 Man Is Not a Bird. Camera Lucida 5:30-48. 